Int. J. Electrochem. Sci., 14 (2019) 9858 - 9875

\title{
Cathodic Protection System Applied to Steel Using Fiber Sheet and Al-based Alloy Anode in Atmospheric Environment
}

\author{
Muye Yang ${ }^{1}$, Shigenobu Kainuma ${ }^{1, *}$, Shusen Zhuang ${ }^{1}$, Shuji Ishihara ${ }^{2}$, \\ Akira Kaneko ${ }^{3}$, and Takao Yamauchi ${ }^{4}$ \\ ${ }^{1}$ Department of Civil Engineering, Faculty of Engineering, Kyushu University, Fukuoka 8190395, \\ Japan \\ ${ }^{2}$ Research \& Development Hq. Tamano Technology Center, Mitsui Engineering \& Shipbuilding Co., \\ Ltd. Tamano 706-0014, Japan \\ ${ }^{3}$ Surface Innovation Group, Nikkei Research \& Development Center, Nippon Light Metal Company \\ Ltd., Shizuoka 421-3291, Japan \\ ${ }^{4}$ Production Division, Saidaiji Plant, Japan Exlan Co., Ltd., Okayama 704-8194, Japan \\ *E-mail: kai@doc.kyushu-u.ac.jp
}

doi: $10.20964 / 2019.10 .40$

Received: 31 May 2019 / Accepted: 2 July 2019 / Published: 30 August 2019

In this study, we developed a cathodic protection (CP) system, which includes a sacrificial anode and a moisture-absorbent fiber sheet, and applied it to old steel structures exposed in a chloride environment, especially localized steel members susceptible to corrosion. Additionally, we evaluated the effects of environmental changes caused by the electrolyte and anodic material on the durability and effectiveness of the CP system. To verify the corrosion kinetics of steel affected by the sacrificial anode, electrochemical tests on binary and ternary alloys were conducted in an immersion environment and the corresponding electrochemical tests on specimens with $\mathrm{CP}$ were conducted in an indoor atmospheric environment. Moreover, the anti-corrosion mechanism and time-dependent current variations were clarified by conducting exposure corrosion tests. The test results demonstrated that the anodic reaction kinetics of Al-3Zn and Al-20Zn were similar; Al-based alloy could be a sacrificial anode with a stable activating reaction, providing sustained $\mathrm{CP}$ for steel through an aquiferous fiber sheet. Furthermore, the fiber sheet acted as an effective electrolyte in the atmospheric environment and led to a sustained anticorrosion current and negative potential at the steel member. In addition, high chloride or nonuniform electrolyte was considered the reason for the occurrence of self-corrosion in a steel plate, which can be avoided by adjusting the dimensions of the exposed holes in the anode plate.

Keywords: steel structure; atmospheric corrosion; passive cathodic protection; Al-based alloy; electrochemical test 


\section{FULL TEXT}

(C) 2019 The Authors. Published by ESG (www.electrochemsci.org). This article is an open access article distributed under the terms and conditions of the Creative Commons Attribution license (http://creativecommons.org/licenses/by/4.0/). 